\title{
Esofagitis tuberculosa en un paciente HIV positivo
}

\author{
G ustavo Bresky $\mathbf{R}^{1}$, N elly Silva $\mathbf{Z}^{\mathrm{a}}$, Juan Madariaga $\mathbf{G}^{\mathbf{1}}$. \\ Esophageal tuberculosis. \\ Report of one case with aids
}

Tuberculosis rates in Chile are higher than expected during the last years. This is directly related to the increase of immunodeficiency associated to human immunodeficiency virus (HIV) infection. Gastrointestinal tuberculosis is the sixth in frequency of extra pulmonary localizations. We report an $\operatorname{HIV}(+) 55$ year-old male, that presented with fever and epigastric pain. In an upper GI endoscopy, small elevated lesions were described in the esophagus. Pathological study was suggestive of tuberculous infection. The definitive diagnosis of esophageal tuberculosis was obtained by a PCR test of the biopsy sample. Antituberculous therapy was started and one year later there was a regression but not disappearance of esophageal lesions and granulomas in the pathological study (Rev Méd Chile 2007; 135: 1323-26).

(Key words: Esophagoscopy, HIV, Tuberculosis esophageal)

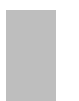

Recibido el 11 de mayo, 2006. Aceptado el 25 de enero, 2007.

${ }^{1}$ Escuela de Medicina Universidad Católica del Norte, Chile.

aAlumna de la Escuela de Medicina, Universidad Católica del Norte, Chile.

L a Organización Mundial de la Salud estima que cada año aparecen más de 8 millones de nuevos casos de tuberculosis (TBC). El 95\% de ellos ocurre en países en vías de desarrollo, donde el virus de la inmunodeficiencia humana (VIH) es común ${ }^{1}$.

Actualmente, según el Departamento de Estadística e Información del Ministerio de Salud de Chile, nuestro país presenta una tasa de incidencia de TBC menor a 18 por cada 100.000 habitantes, ubicándose dentro del grupo de menor incidencia americana. A pesar de ello, durante los últimos años, las tasas de TBC observadas en Chile durante los años 2001-2002 están por sobre lo esperado, de acuerdo a la extrapolación de la tendencia de morbilidad notificada entre 1990 y 1999, en la que se apreciaba un descenso sostenido de ella ${ }^{2}$. Esto

Correspondencia a: Dr. Gustavo Bresky R. Las Américas 1804, La Serena, Chile. Fono-Fax: 5651 228110. E mail: bresky@ucn.cl se atribuye a diversos factores, dentro de los cuales aparece el incremento del número de personas con inmunodeficiencia asociada a infección por el virus de la inmunodeficiencia humana (VIH).

La región de Coquimbo presenta una tasa de incidencia de TBC de 13,9 x 100.000 habitantes, ubicándose bajo la media nacional (17,4 x 100.000 habitantes). Como Servicio de Salud, integra el Grupo de Servicios en Fase de Eliminación de la TBC, mientras que la prevalencia de infectados por VIH en la región, es un reflejo de lo que sucede en el país, con un aumento franco en los últimos años ${ }^{2}$.

La esofagitis tuberculosa es una localización infrecuente de tuberculosis extrapulmonar $(0,14 \%$ en las autopsias de pacientes fallecidos por TBC) ${ }^{3}$. Aún no existen casos notificados de tuberculosis esofágica en nuestra región y no conocemos de alguno a nivel nacional.

Se presenta el caso de un hombre adulto $\mathrm{VIH}(+)$ con compromiso del estado general y con alteraciones endoscópicas, que sumado a hallazgos histológicos de dichas lesiones, inician la sospecha 
de infección tuberculosa extrapulmonar. Tanto el estudio histológico de tejido esofágico, como el examen de reacción de polimerasa en cadena (PCR) confirmaron, en un corto plazo, el diagnóstico de esofagitis por Mycobacterium tuberculosis, lo que permitió el inicio de tratamiento antituberculoso con remisión total del cuadro clínico y parcial de lesiones macroscópicas en el esófago.

Caso clínico. Paciente de sexo masculino de 55 años, $\mathrm{VIH}(+)$ de reciente diagnóstico, con carga viral de 5.400 copias de ARN viral/ml, CD3 $997 \mathrm{cel} / \mu \mathrm{L}$ (71\%) y CD3/CD4 $239 \mathrm{cel} / \mu \mathrm{L}$ (17\%), no había recibido tratamiento antirretroviral. No refenía antecedentes previos de TBC ni de contacto con paciente infectado.

Consultó por compromiso del estado general, baja de peso de $10 \mathrm{~kg}$ aproximadamente en 4 meses, asociado a náuseas, epigastralgia y diaforesis nocturna ocasional. El paciente no refería síntomas respiratorios, urinarios, ni digestivos.

$\mathrm{Al}$ examen físico inicial destacaba paciente enflaquecido, normotenso, frecuencia cardíaca 100 lat/min y $37,5^{\circ} \mathrm{C}$ de temperatura axilar, no se evidencian adenopatías; el examen cardiopulmonar era normal y el abdomen no presentaba masas ni visceromegalias.

Los exámenes iniciales mostraron: hemograma con hematocrito de 39\%; 11.300 leucocitos (sin desviación a izquierda); plaquetas normales y VHS de $68 \mathrm{~mm} / \mathrm{h}$. Ecotomografía abdominal y radiografía de tórax anteroposterior y lateral normales.
Se solicitó endoscopia digestiva alta que mostró mucosa esofágica de superficie irregular, que formaba tres cordones mamelonados confluyentes hacia el cardias con algunas placas blanquecinas adherentes compatibles con cándida esofágica (Figura 1); estómago y duodeno no mostraron hallazgos patológicos.

Las biopsias del tejido esofágico informaron «sofagitis crónica granulomatosa ulcerada de tipo tuberculoso» (Figura 2). Se descartaron alteraciones citopáticas virales con tinción hematoxilina eosina. Con la tinción de Grocott no se reconocieron estructuras micóticas y con la tinción de ZiehlNeelsen no se observaron bacilos alcohol ácido resistentes. Se solicitó estudio con reacción de polimerasa en cadena (PCR) del tejido biópsico al Departamento de Anatomía Patológica de la Pontificia Universidad Católica de Chile, donde se utilizó una técnica in-house validada por el Instituto de Salud Pública, con controles internos y externos. La muestra constaba de tres cortes histológicos de 5 micrones de áreas representativas. Fue colocada en tubos $1,5 \mathrm{ml}$ y resuspendida en $100 \mu$ l de tampón de extracción con proteinasa $\mathrm{K}$. Se incubó a $55^{\circ} \mathrm{C}$ por $12 \mathrm{~h}$ y a $100^{\circ} \mathrm{C}$ por 10 min, luego fue centrifugada a $12.000 \mathrm{rpm}$ y el sobrenadante fue traspasado a tubos estériles, mantenido a $-30^{\circ} \mathrm{C}$ hasta su amplificación. Se realizó PCR para detectar la presencia de mycobacterium tuberculosis por amplificación en du-

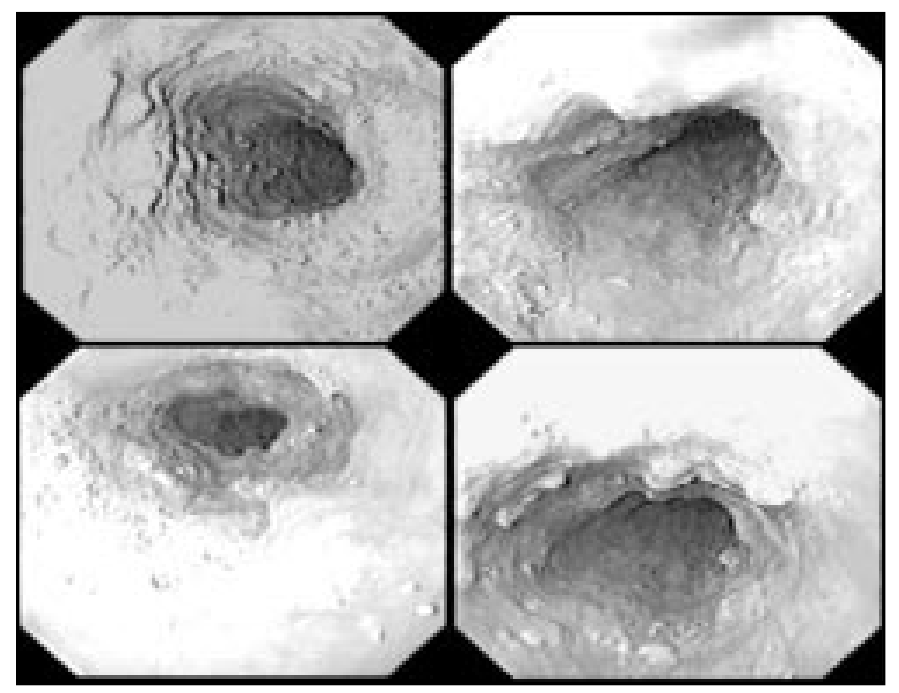

Figura 1. Endoscopia digestiva alta (febrero 2003). Mucosa esofágica irregular, mamelonada, con presencia de algunas placas blanquecinas adherentes, compatibles con cándida esofágica. 


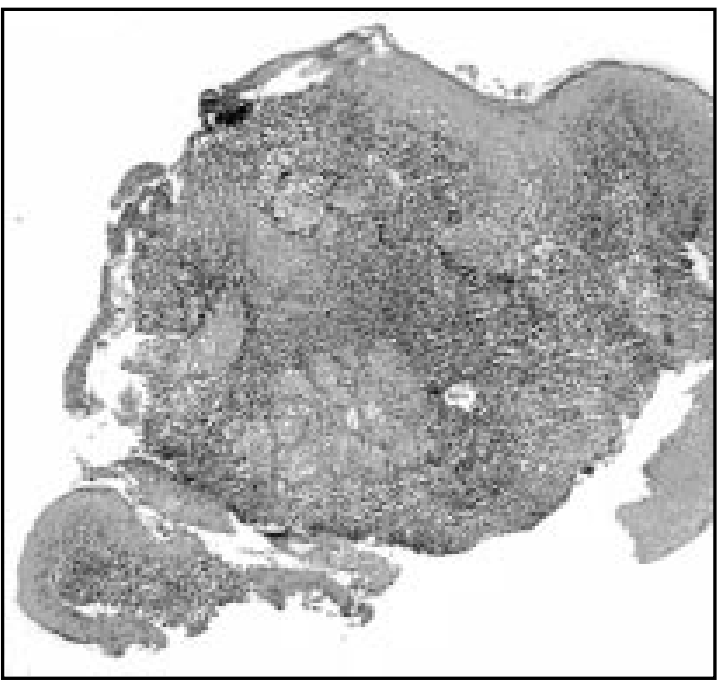

Figura 2. Micrografía mucosa esofágica (febrero 2003). Muestra constituida por mucosa esofágica revestida por epitelio escamoso estratificado no queratinizante con algunos granulocitos neutrófilos intraepiteliales. Lámina propia con moderado infiltrado inflamatorio constituido por linfocitos y plasmocitos. Focalmente se reconocen granulomas no caseificantes. Tinción Hematoxilina y Eosina.

plicado de la secuencia IS6110, específica para mycobacterium tuberculosis complex ${ }^{4}$, con una especificidad de 83,9\%-100\% y sensibilidad de 80\%-91,3\% ${ }^{5}$. En paralelo, se realizó evaluación de integridad de $\mathrm{ADN}$ de la muestra por amplificación del gen beta-globina humana (control positivo interno $)^{6}$ y una de muestra en blanco para descartar la posibilidad de contaminación (control negativo externo). Los productos de PCR fueron visualizados en electroforesis de agarosa al $3 \%$. Se concluyó que la PCR fue positiva para la detección de mycobacterium tuberculosis, con control interno positivo y externo negativo.

Posteriormente se evidenciaron baciloscopias de esputo positivas. Más tarde, el cultivo confirmó la variedad de mycobacterium tuberculosis hominis.

Se inició terapia antituberculosa con isoniacida, rifampicina, pirazinamida y etambutol según norma (previo a la confirmación del cultivo), con lo que se logró mejoría de síntomas inespecíficos al mes de iniciado el tratamiento, negativización de las baci- loscopias a los 3 meses, destacando que el paciente no recibió otros tratamientos antimicrobianos 0 antifúngicos. A los 6 meses existía mejoría de peso, VHS y demás síntomas. Controles endoscópicos al año de evolución, mostraron regresión importante, pero no completa de las lesiones macroscópicas, con histología que evidenciaba candidiasis esofágica y gastritis fúndica, pero con desaparición de las lesiones granulomatosas.

\section{Discusión}

Del total de los pacientes que cursan con TBC, 10\%-20\% corresponde a localizaciones extrapulmonares. Dicho porcentaje aumenta de manera considerable (45\%-75\%) en pacientes con infección por el $\mathrm{VIH}^{7}$.

El carácter de inmunodeprimido del paciente del presente caso, constituye un factor de riesgo importante en el desarrollo de TBC de localización atípica. Presumiblemente, la base de la alta frecuencia de tuberculosis extrapulmonar entre pacientes infectados por VIH es la falla de la respuesta inmune contra mycobacterium tuberculosis, permitiendo la diseminación hematógena y subsiguiente mono o polinvasión de tejidos extrapulmonares ${ }^{1}$.

La afectación gastrointestinal en la tuberculosis es rara $(0,5 \%-4 \%)^{8}$ y corresponde a la sexta frecuencia de las localizaciones extrapulmonares ${ }^{3}$. La presentación clínica de la esofagitis tuberculosa, al igual que cualquier otra manifestación tuberculosa, es inespecífica, siendo los síntomas más frecuentes la disfagia, odinofagia, fiebre, dolor epigástrico y pérdida de peso con o sin anorexia ${ }^{3}$.

En general, el diagnóstico de tuberculosis extrapulmonar es difícil por ser poco común y por lo tanto, existir menor familiaridad con su presentación clínica. Por otro lado, la tuberculosis extrapulmonar invade sitios relativamente inaccesibles y con una baja carga bacteriana, lo que dificulta aún más el diagnóstico, obligando a requerir procedimientos invasivos para su confirmación ${ }^{1}$. El diagnóstico definitivo de una tuberculosis esofágica vendrá determinado por la presencia de granulomas en la biopsia esofágica, y fundamentalmente por el crecimiento de mycobacterium tuberculosis en el cultivo ${ }^{3}$, habiéndose descartado la presencia de otros agentes etiológicos mediante tinciones al tejido biópsico. 
La detección de ADN de mycobacterias mediante PCR es una técnica rápida (permite obtener un diagnóstico en 1 a 3 días) y altamente eficaz ${ }^{9}$. La utilidad de este examen radica principalmente en la identificación en corto plazo de la especie, lo cual es importante en los casos de TBC pulmonar y $\mathrm{HIV}(+)$ asociado. Esta técnica amplifica la molécula de ADN y permite identificar la presencia de menos de 10 bacilos de una muestra, aunque no distingue bacilos vivos de los muertos, es decir, TBC activa de inactiva. Tiene una sensibilidad variable (27\%$81 \%)$ y una alta especificidad $(67 \%-100 \%)^{10-12}$ en el diagnóstico de TBC extrapulmonar. En comparación con otros estudios complementarios podría tener una ventaja comparativa ante la baja carga bacteriana característica de la TBC extrapulmonar.

Otro aspecto interesante de considerar es que, tal como ocurrió en este caso, al momento de obtener las muestras de tejido esofágico no se sospechó la existencia de una tuberculosis y por lo tanto el material fue puesto en glutaraldehído. Por ello, al momento de tener la orientación diagnóstica basada en el informe histopatológico,

\section{REFERENCIAS}

1. Dunlap N, Bass J, Fujiwara P, Hopewell P, HorsBURGH C ET AL. Diagnostic Standands and Classification of Tuberculosis in Adults and Children. Am J Respir Crit Care Med 2000; 161: 1376-95.

2. ZúNIGA M. Situación de la tuberculosis en Chile 2002 y su posible evolución. Rev Chi Enf Respir 2003; 19: 179-91.

3. Gómez A, Garrido C, Sansó A, Torres JJ, Castriuejo C. Tuberculosis esofágica en paciente inmunocompetente. Gastroenterol Hepatol 2003; 26: 643-5.

4. Fletcher H. Molecular epidemiology of tuberculosis: recent developments and applications. Curr Opin Pulm Med 2001; 7: 154-9.

5. Kaltwasser G, García S, Salinas A, Rioseco M, MoNTIEL F. Amplification of 2 different gene segments of Mycobacterium tuberculosis and its usefulness in the diagnosis of tuberculosis. Rev Méd Chile 1993; 121: 1359-66.

6. Saiki R, Chang C, Levenson C, Warren T, Bothm C, KazAZiAn H ET AL. Diagnosis of sickle cell anemia and beta-thalassemia with enzymatically amplified DNA and nonradioactive allele-specific oligonu- el tejido no podía ser enviado a cultivo, pero se pudo obtener de esas mismas muestras el material necesario para realizar la técnica de PCR.

A pesar del valor de esta herramienta diagnóstica, su uso no debe sobreestimarse. El cultivo sigue siendo el patrón de oro del diagnóstico y la baciloscopia es muy útil cuando es bien realizada. En los casos con sospecha clínica en los que no se ha realizado baciloscopia y cultivo, la interpretación de un resultado por detección de ADN de mycobacterium tuberculosis por PCR, deberá analizarse en un contexto crítico y siguiendo un juicio clínico adecuado. La PCR para la detección de ADN de mycobacterium tuberculosis y otras micobacterias constituye actualmente una altemativa diagnóstica con gran futuro como método de referencia ${ }^{11,12}$.

La existencia de este caso reafirma la importancia de considerar las localizaciones tuberculosas infrecuentes especialmente en pacientes inmunodeprimidos. Igualmente es importante destacar el valor de un buen estudio histolopatológico y de estudios complementarios como la PCR de material biópsico para el rápido diagnóstico en pacientes de alto riesgo.

cleotide probes. N Engl J Med 1988; 319: 537-41.

7. Maroto N, Ponce M. Tuberculosis y Aparato Digestivo. Gastroenterol Hepatol 2003; 26: 34-41.

8. Malca L, Torreblanca J, Astato C, Velasco L. Tuberculosis de esófago: reporte de un caso. Rev Gastroenterol Per 2003; 23: 67-9.

9. Parra J, Onrubia X, Selier J, Pertusa V, Barberá M. Tuberculosis Extrapulmonar en un Paciente con Shock Séptico. Rev Esp Anestesiol Reanim 2002; 49: 48-50.

10. Beiges J, Lokies J, Schaberg T, Finckh U, Fischer M, Mauch H ET AL. Clinical Evaluation of a Mycobacterium Tuberculosis PCR Assay. J Clin Microbiol 1995; 33: 90-5.

11. Noordhoek G, Kolk A, Bjune G, Catty D, Dale J, Fine $P$ ET AL. Sensitivity and Specifity of PCR for detection of Mycobacteium Tuberculosis: A Blind Comparison Study amog Seven Laboratorios. J Clin Microbiol 1994; 32: 277-84.

12. D'Amato R, Wallman A, Hochstein L, Colaninno P, Scardamagla M, ARdila E et al. Rapid Diagnosis of Pulmonary Tuberculosis by using Roche AMPLICOR Mycobacterium Tuberculosis PCR Test. J Clin Microbiol 1995; 33: 1832-34. 